\title{
Violência obstétrica contra a gestante com deficiência
}

\author{
Obstetric violence against a disabled pregnant
}

\author{
Aline de Miranda Valverde Terra* \\ Ana Carla Harmatiuk Matos*
}

\section{Resumo}

O artigo tem como escopo pugnar, com base em revisão bibliográfica e análise legislativa, pela autodeterminação dos direitos sexuais e reprodutivos para todas as mulheres. Tal autonomia deve englobar inclusive o "plano de parto", numa concepção humanizada. Dedica-se, de modo especial, à defesa desse direito para as pessoas com deficiência física, psíquica ou intelectual, na esteira do que determina a Convenção da ONU sobre os Direitos da Pessoa com Deficiência, incorporada ao ordenamento brasileiro com status de emenda constitucional, bem como o Estatuto da Pessoa com Deficiência.

Palavras-chave: Gestante. Pessoa com deficiência. Plano de parto. Violência obstétrica.

\section{Abstract}

The article aims at advocating, based on bibliographic review and legislative analysis, for the self - determination of sexual and reproductive rights for all women. Such autonomy must encompass even the "birth plan" in a humanized conception. The protection of this right for people with physical, psychic or intellectual disabilities is specifically pursued in accordance with the UN Convention on the Rights of Persons with Disabilities, incorporated into the Brazilian legal system with constitutional amendment status, as well as the Statute of the Person with Disabilities.

Keywords: Pregnant. Disabled person. Birth plan. Obstetric violence.

\section{Introdução}

Em 2006, aos sete meses de gestação, a bolsa estourou. Eva se dirigiu à maternidade, onde ficou internada por dois dias, e encaminhada para casa. Ao retornar ao hospital, três dias depois, de acordo com a orientação que recebera, foi recebida com agressões e acusações: "Por que não veio mais cedo?", "Queria forçar um parto normal?", "Quem manda no procedimento sou eu". Eva foi, então, encaminhada à sala de cirurgia, e ouviu de um dos profissionais que a atendia que iria "arcar com as consequências" de suas escolhas. A equipe médica tentou realizar a manobra de Kristeller, e uma das enfermeiras, sem a consultar, deitou sobre sua barriga. Eva reagiu ao procedimento e teve suas mãos amarradas. O bebê não sobreviveu. A mãe ouviu que a morte de seu filho ocorrera por ela ter "forçado" o parto. Eva sequer teve acesso ao prontuário médico. ${ }^{1}$

Doutora e mestre em Direito Civil pela Universidade do Estado do Rio de Janeiro. Professora adjunta do Departamento de Direito Civil da Universidade do Estado do Rio de Janeiro. Professora do Departamento de Direito Civil da Pontifícia Universidade Católica do Rio de Janeiro e de cursos de pós-graduação da UERJ e da PUC/Rio. Coordenadora editorial da Revista Brasileira de Direito Civil - RBDCivil. Pesquisadora visitante do Instituto Max-Planck de Direito Privado Comparado e Internacional em Hamburgo - Alemanha. Rio de Janeiro-RJ- Brasil. E-mail: ammvalverde@hotmail. com.

Doutora pela Universidade Federal do Paraná. Mestra em Direito pela Universidade Federal do Paraná. Mestra em Derecho Humano pela Universidad Internacional de Andalucía. Tuttora Diritto na Universidade di Pisa - Itália. Professora na graduação, no mestrado e no doutorado em Direito da Universidade Federal do Paraná. Vice-Coordenadora do Programa de Pós-graduação em Direito da Universidade Federal do Paraná. Diretora da Região Sul do IBDFAM. Vice-Presidente do IBDCivil. Curitiba-PR-Brasil. E-mail: a.c.matos@uol.com.br.

O episódio é narrado em reportagem da Revista Época, sob o título "Vítimas da violência obstétrica: o lado invisível do parto" (LAZZAREI, 2015). 
Este é apenas um relato chocante em meio a milhares de outros que retratam uma lamentável realidade que afeta uma em cada quatro mulheres no Brasil. ${ }^{2} \mathrm{~A}$ violência obstétrica, uma prática abusiva contra as gestantes que, a despeito de não ser recente, ${ }^{3}$ começa a ganhar atenção, cada vez maior, dos juristas nacionais.

Este artigo se propõe, com efeito, a analisar a violência obstétrica contra um grupo particular de gestantes: aquelas com deficiência. Para tanto, verificar-se-á como o modelo médico de deficiência contribuiu para a adoção, pela codificação civil de 1916 e 2002, de um modelo abstrato de incapacidade, e como esse modelo conduziu à despersonificação das pessoas com deficiência, a naturalizar todas as formas de violência praticadas contra elas, inclusive a obstétrica. Em seguida, analisar-se-á como a adoção, pelo Estatuto da Pessoa com Deficiência, do modelo social de deficiência rompeu com essa lógica, alterando o regime das incapacidades e promovendo a autonomia jurídica e social das pessoas com deficiência, o que impacta diretamente na imperatividade de observância de sua vontade no que tange a todos os procedimentos ligados à gestação, inclusive em relação às diretrizes veiculadas no seu plano de parto.

\section{Violência obstétrica: novas luzes sobre um revelho problema}

De acordo com a cartilha informativa lançada pela Defensoria Pública do Estado de São Paulo (DPGESP), em 2013, a violência obstétrica se caracteriza pela

[...] apropriação do corpo e processos reprodutivos das mulheres pelos profissionais de saúde, através do tratamento desumanizado, abuso da medicalização e patologização dos processos naturais, causando a perda da autonomia e capacidade de decidir livremente sobre seus corpos e sexualidade, impactando negativamente na vida das mulheres (SÃO PAULO. DPGE-SP, 2013).

O tratamento desumanizado se verifica sempre que a mulher tem sua dignidade aviltada, seja por meio de atos que violem sua integridade psíquica, como se passa quando a equipe médica dispensa à mulher tratamento humilhante, xingando-a ou depreciando-a, bem como quando lesam sua integridade física, a exemplo do que ocorre quando se adotam procedimentos sem o seu consentimento, tais como: lavagem intestinal, tricotomia (raspagem dos pelos pubianos), imobilização física, exames de toques constantes e desnecessários, manobra de Kristeller (procedimento pelo qual o profissional de saúde "empurra" a barriga da gestante a fim de acelerar a expulsão do feto), episiotomia (corte cirúrgico na região do períneo para ampliar o canal de parto) de rotina, e mesmo cesariana sem anestesia. Cuida-se de práticas abusivas, muitas sem respaldo científico, adotadas por decisão exclusiva do médico, sem o consentimento livre e esclarecido da parturiente. ${ }^{4}$ Trata-se, com efeito, de procedimentos rotineiros nos hospitais do país, ineficazes ou pouco eficazes, alguns reconhecidamente inseguros, e que causam desconforto, dor, humilhação ou constrangimento. ${ }^{5}$

O abuso da medicalização, por sua vez, é identificado sempre que se realizam intervenções médicas desnecessárias, levadas a cabo com a finalidade exclusiva de beneficiar o médico ou o hospital no qual o parto é realizado, e cujos resultados poderiam ser alcançados por meio de intervenções menos gravosas para a

" $25 \%$ das mulheres entrevistadas afirmaram ter sofrido alguma forma de violência institucional, desatacando-se a realização de exame de toque doloroso e negativa para alívio da dor (10\%), ausência de explicação quanto aos procedimentos adotados e gritos de profissionais durante o atendimento $(9 \%)$, negativa de atendimento $(8 \%)$ e xingamento e humilhações (7\%). Ainda, a pesquisa apontou que cerca de $23 \%$ das entrevistadas sofreram coação verbal pelos profissionais, por meio de frases como 'não chora que ano que vem você está aí de novo' (15\%), 'na hora de fazer não chorou, não chamou a mamãe' (14\%), 'se gritar eu paro e não vou te atender' $(6 \%)$, 'se ficar gritando vai fazer mal pro neném, ele vai nascer surdo' (5\%)" (FUNDAÇÃO PERSEU ABRAMO, 2010, p. 173 e seguintes).

3 A título de exemplo, confira-se o seguinte trecho de Henci Goer, que remete a artigo publicado há mais de 50 anos, nos Estados Unidos, acerca da violência obstétrica que então já se verificava: “'Cruelty in Maternity Wards' was the title of a shocking article published just over 50 years ago in Ladies' Home Journal in which nurses and women told stories of inhumane treatment in labor and delivery wards during childbirth (SCHULTZ, 1958). Stories included women being strapped down for hours in the lithotomy position, a woman having her legs tied together to prevent birth while her obstetrician had dinner, women being struck and threatened with the possibility of giving birth to a dead or brain damaged baby for crying out in pain, and a doctor cutting and suturing episiotomies without anesthetic (he had once nearly lost a patient to an overdose) while having the nurse stifle the woman's cries with a mask" (HENCl, 2010).

4 "Consentimento esclarecido é aquele que tem como base o integral cumprimento do dever médico de explicar ao doente, de modo compreensível e leal, o tratamento que se propõe fazer, quais os prováveis efeitos e quais os riscos possíveis, ainda que pouco usuais. Do mesmo modo exige-se que o médico explique ao doente quais as possibilidades de tratamento" (DIAS, 1996, p. 292).

5 Tal realidade tem sido enfrentada pelos tribunais brasileiros: TJ-RS, 6 ${ }^{\text {a }}$ CC, Apelação Civel n. 70021336938, Rel. Des. Artur Arnildo Ludwig. J. 13.9.2009. 
gestante, como quando se usa indiscriminadamente a versão sintética da ocitocina para agilizar o trabalho de parto e se realiza cesárea sem indicação clínica, contrariando a vontade da gestante de realizar parto normal, por simples conveniência de agenda do obstetra.

Por fim, a patologização dos processos naturais se caracteriza pela utilização de procedimentos, por vezes também dispensáveis e desproporcionais, com o objetivo de promover maior segurança para a gestante e para o bebê, a exemplo do que se passa quando se realiza uma cesárea porque a gestante ainda não alcançou a dilatação suficiente.

Durante anos, assistiu-se com certa naturalidade a todas essas práticas, decorrentes, em grande medida, da medicalização do parto, cujo escopo se concentra em atribuir a tais profissionais o absoluto controle sobre todas as etapas da gestação, desde a fase anterior à concepção até o pós-parto, colocando em suas mãos todas as decisões relativas ao processo gestacional, bem como da disseminação da concepção segundo a qual os profissionais de saúde têm o direito de acessar livremente o corpo feminino. ${ }^{6}$ Referida postura, somada à perpetuação do ensino acrítico aos estudantes de Medicina de procedimentos dolorosos e, não raro, prescindíveis, acaba por normalizar aquelas práticas antes referidas, estabelecendo uma cultura institucional que não as reconhece como violações aos direitos da gestante.

Exemplo eloquente dessa cultura institucional é a episiotomia, disseminada nas escolas médicas como a primeira oportunidade de os estudantes, de qualquer especialidade, praticarem habilidades cirúrgicas, cortando e suturando a vagina de mulheres pobres. Emblemática desse propósito foi a expressão cunhada para ilustrar essa exposição desmedida e não consentida da genitália feminina nos hospitais universitários: "vagina-escola".7

Nesse cenário, o desrespeito aos desejos e vontades da gestante se naturalizou e institucionalizou de tal forma que, muitas vezes, ela sequer consegue se perceber vítima de violência obstétrica. Foi justamente o que aconteceu com Kelly, que só entendeu o que lhe havia acontecido após compartilhar sua experiência em grupo fechado de mães em rede social. Segundo seu relato, ao chegar à maternidade, o marido foi impedido de acompanhá-la, sendo-lhe negado direito assegurado, desde 2005, pela Lei $n^{\circ} 11.108$, que obriga hospitais, maternidades e assemelhados a permitir um acompanhante, à escolha da gestante, no trabalho de parto, durante o parto e no pós-parto imediato (até 10 dias após o parto). ${ }^{8}$ Mas não só isto. Quando começou a sentir as fortes dores das contrações, ouviu da equipe médica: "Na hora de fazer, não gostou?" e "não grita, vai assustar as outras mães".

Após o nascimento do bebê, deram-lhe o que designaram "ponto do marido", para "continuar casada": não bastasse a realização de episiotomia sem o conhecimento de Kelly, o médico, ao fazer a sutura, deu um ponto a mais, para apertar a abertura da vagina. As dores decorrentes do procedimento realizado à sua revelia acompanham Kelly desde então (LAZZAREI, 2015). Percebe-se, então, que

[...] as questões de saúde, de nascer e morrer, originariamente objeto de preocupação e cuidados femininos, passaram às mãos e mentes dos homens com o desenvolvimento da medicina moderna. $O$ mesmo processo ocorreu com o parto tendo os médicos assumido o posto tradicionalmente ocupado pelas parteiras, desvalorizando a sensibilidade e o papel das mães (COSTA; LUNA, 2016, s.p.).

A fim de combater episódios como estes, a Organização Mundial de Saúde (OMS) publicou, em 23 de setembro de 2014, declaração oficial para prevenção e eliminação da violência obstétrica, que qualificou como

6 Os "procedimentos hospitalares padrões" nos partos podem ser considerados como um modo de exercício de poder sobre os corpos femininos, revelando técnicas de dominação e reforçando uma obediência não opcional. Nesse sentido aproximamos tais críticas com as reflexões a respeito dos chamados corpos dóceis: "É dócil um corpo que pode ser submetido, que pode ser utilizado, que pode ser transformado e aperfeiçoado" (FOUCAULT, 1997, p. 132).

O termo "vagina-escola" foi usado por entrevistados em uma pesquisa do grupo, realizada no âmbito de evento intitulado "A vagina-escola: seminário sobre violência contra a mulher no ensino das profissões de saúde”, em março de 2015, na Faculdade de Saúde Pública da USP, para se referir à formação dos profissionais médicos (DINIZ; NIY; ANDREZZO; CARVALHO; SALGADO, 2016, p. 253).

8 A Lei $n^{\circ} 11.108 / 2005$ incluiu o art. 19-J na Lei nº 8.080/1990, com a seguinte redação: “Art. 19-J. Os serviços de saúde do Sistema Único de Saúde - SUS, da rede própria ou conveniada, ficam obrigados a permitir a presença, junto à parturiente, de 1 (um) acompanhante durante todo o período de trabalho de parto, parto e pós-parto imediato. $\S 1^{\circ} \mathrm{O}$ acompanhante de que trata o caput deste artigo será indicado pela parturiente. $\S 2^{\circ}$ As ações destinadas a viabilizar o pleno exercício dos direitos de que trata este artigo constarão do regulamento da lei, a ser elaborado pelo órgão competente do Poder Executivo." 
violação dos direitos humanos fundamentais. De acordo com a OMS, os relatos sobre os abusos praticados incluem

\begin{abstract}
[...] violência física, humilhação profunda e abusos verbais, procedimentos médicos coercivos ou não consentidos (incluindo a esterilização), falta de confidencialidade, não obtenção de consentimento esclarecido antes da realização de procedimentos, recusa em administrar analgésicos, graves violações da privacidade, recusa de internação nas instituições de saúde, cuidado negligente durante o parto levando a complicações evitáveis e situações ameaçadoras da vida, e detenção de mulheres e seus recém-nascidos nas instituições, após o parto, por incapacidade de pagamento (OMS, 2014, s.p.).
\end{abstract}

A gravidade da situação é, com efeito, inquestionável, e revela violação frontal ao direito fundamental ao parto humanizado, garantidor à gestante da escolha de um modelo não padronizado de parto, que atenda à sua singularidade e personalidade, conferindo-lhe poder de decisão sobre os procedimentos a serem seguidos e aqueles que não deseja que sejam adotados, retomando o protagonismo feminino.$^{9} \mathrm{~A}$ propósito, a Organização Mundial da Saúde corrobora a proposta de parto humanizado, cujo foco está na transformação do nascimento em experiência positiva para a mulher e o bebê, e define diretrizes práticas para os variados protagonistas desse momento: mãe, médico, parteira, doula, enfermeiros, acompanhantes, entre outros (WHO, 2018).

Há, contudo, um grupo de mulheres ainda mais indefesas, hipervulneráveis, ${ }^{10}$ que se encontram em situação de maior desamparo e que sofrem de forma mais intensa e cruel com práticas violentas e hostis ligadas à gestação: as mulheres com deficiência. Nessa perspectiva, Heloisa Helena Barboza (2009, p. 110-111) entende que os idosos, assim como crianças, adolescentes e pessoas com deficiência, são circunstancialmente afetados e fragilizados, isto é, são "vulnerados" e demandam a aplicação de normas que compreendam a desigualdade materialmente reproduzida para que sua dignidade seja resguardada (BARBOZA, 2008, p. 61).

Esse contingente populacional, dado as sobreposições de gênero e deficiência, vivencia especificidades que tornam ainda mais evidente a sua precarização (BUTLER, 2015, p. 46-47). Essa realidade decorre, em alguma medida, da histórica adoção de um regime das incapacidades baseado no modelo médico da deficiência, que não apenas negava capacidade e autonomia à pessoa com deficiência, resultando na sua objetificação e completa desconsideração de seus desejos e vontades, como também entendia a deficiência como um "problema" exclusivamente da pessoa que a apresentava, impondo-lhe - no mais das vezes - 0 intransponível ônus de se adaptar à sociedade. É o que se constata a seguir.

\title{
3 O modelo médico da deficiência e o regime abstrato da incapacidade da pessoa com deficiência: portas abertas para a violência obstétrica
}

No Brasil, como em todo o mundo, o conceito de deficiência vem passando por profundas transformações a fim de acompanhar as inovações na área da saúde, bem como a forma pela qual a sociedade se relaciona com a parcela da população que apresenta algum tipo de deficiência.

O modelo médico de deficiência considerava somente a patologia física e o sintoma a ela associado que dava origem a uma incapacidade. Esse modelo foi adotado pelo Código Civil de 1916 e reproduzido no Código Civil de 2002, que estabeleceu disciplina abstrata das incapacidades baseada no sistema de tudoou-nada: a pessoa com deficiência mental, que não tivesse o necessário discernimento para a prática dos

\footnotetext{
"Parto humanizado é essencialmente aquele parto centrado na mulher, com respeito à autonomia e ao protagonismo feminino. Parto natural é o parto que acontece sem intervenções, como ocitocina, analgesia e fórceps. É possível se ter um parto humanizado não inteiramente natural, porque algumas intervenções podem ser necessárias. Por isso, o fundamental é essa retomada do protagonismo feminino no parto" (WOLFART, 2012, s.p.). Decisão recente do Tribunal de Justiça de São Paulo enfrentou caso de violência obstétrica afirmando ser o parto humanizado um direito fundamental: TJSP 00013140720158260082. 5 Câmera de Direito Privado. Rel. Des. Fábio Podestá. Data de julgamento $11 / 10 / 2017$.

10 "A difusão do termo tem origem na decisão: STJ, REsp 1.064.009/SC, 2. ${ }^{a}$ T., Rel. Min. Herman Benjamin, j. 04.08.2009, DJe 27.04.2011. Nessa linha, Adolfo Mamoru Nishiyama e Roberta Densa explicam: "O prefixo hiper (do grego hypér), designativo de alto grau ou aquilo que excede a medida normal, acrescido da palavra vulnerável, quer significar que alguns consumidores possuem vulnerabilidade maior do que a medida normal, em razão de certas características pessoais" (2010, p. 13 e seguintes). V., ainda, Konder (2015).
} 
atos civis, seria considerada absolutamente incapaz, sendo-lhe negado o exercício autônomo de qualquer ato da vida civil; fazia-se imperioso um representante para, em seu lugar, manifestar a vontade necessária à prática de referidos atos. A vontade do representante, portanto, substituía inteiramente a vontade da pessoa com deficiência. Se, no entanto, a pessoa com deficiência mental ostentasse discernimento reduzido, seria considerada relativamente incapaz, e a validade de sua manifestação de vontade se vinculava à conjunta manifestação de vontade de seu assistente. Para os atos da vida civil, de maneira geral, exigia-se também a manifestação do assistente.

O modelo médico acabou por negar a inúmeras pessoas com deficiência, em primeiro lugar, o exercício de parcela de autonomia em relação a atos que teriam plenas condições de exercer livremente, produzindo um regime excludente, que retira da pessoa com deficiência a possibilidade de decidir mesmo sobre os atos mais prosaicos da vida. Em verdade, embora absoluta ou relativamente incapaz, a pessoa com deficiência raramente será desprovida de qualquer possibilidade de manifestação de vontade autônoma, sendo necessário assegurar-lhe espaços de liberdade dentro dos quais possa exercer sua autonomia, por menor e mais singela que seja.

Além disso, e ainda mais grave, o sistema das incapacidades codificado permitia, como regra, a dissociação entre titularidade e exercício também dos direitos inerentes à pessoa humana. Em um sistema abstrato, de tudo-ou-nada, isso acaba por impedir que a pessoa com deficiência pratique todo e qualquer ato ligado diretamente à realização do seu projeto de vida e ao livre desenvolvimento de sua personalidade. E mais: no extremo, semelhante modelo pode mesmo permitir que lhe seja negada a própria qualidade de pessoa humana, pois a dissociação abstrata e absoluta entre titularidade e exercício de direitos inerentes à pessoa humana acaba, na prática, por promover a própria desconsideração das titularidades, fomentando um processo de reificação da pessoa com deficiência, que passa a ser, no máximo, um "quase alguém", à semelhança de Quasímodo, assim qualificado por Victor Hugo em seu "O Corcunda de Notre Dame".11

O estabelecimento de disciplina única para a aferição da capacidade necessária à validade dos atos patrimoniais e existenciais, nos moldes do modelo codificado, se revela, no entanto, incompatível com a axiologia constitucional. $\mathrm{O}$ ordenamento jurídico brasileiro atribui tutela prioritária às situações jurídicas existenciais, e instrumentaliza as situações jurídicas patrimoniais à sua realização. Nessa direção, parece equivocado igualar, a priori e abstratamente, os requisitos relativos ao elemento vontade para a prática de atos patrimoniais e para a prática de atos existenciais. A diferença entre os atos de autonomia patrimonial e existencial é, sobretudo, de fundamento constitucional (PERLINGIERI, 1999, p. 18), o que deve se refletir na identificação de diferentes requisitos de validade da vontade para o exercício de cada um deles.

Nesse contexto, a prática de violência obstétrica contra mulheres com deficiência se tornou ainda mais "normalizada" e institucionalizada do que aquela praticada contra mulheres sem deficiência. ${ }^{12}$ Ora, se a deficiência era uma patologia física mais o seu sintoma, cuidava-se de questão afeta, exclusivamente, à pessoa dela portadora, que deveria, então, envidar todos os esforços para se adaptar à sociedade. A partir dessa percepção, se não era a sociedade que deveria criar mecanismos para superação das barreiras que impediam a total inclusão das pessoas com deficiência, como exigir dos hospitais e clínicas, por exemplo, a utilização de equipamentos adaptados às diversas deficiências físicas, ou que os profissionais estejam aptos a lidar com as especificidades inerentes a cada tipo de deficiência?

Retrato desse despreparo é o emblemático caso de uma parturiente surda que, embora soubesse que estava grávida, não sabia que eram gêmeos. Após o nascimento da primeira criança, como a equipe

11 Nas palavras do autor: "Batizou o filho adotivo e deu-lhe o nome de Quasímodo, por querer lembrar o dia em que fora encontrado, ou por querer caracterizar com esse nome o quanto a pobre pequena criatura era incompleta e malfeita. Quasímodo, de fato, caolho, corcunda e capenga, não passava de um quase" (HUGO, 1832, p. 180).

12 Butler (2015, p. 68) destaca que reações de comoção são tacitamente reguladas por certos tipos de enquadramento interpretativo, fazendo com que as pessoas sintam mais horror e repulsa moral por vidas humanas. Segundo a autora, a resposta moral à violência decorre da concepção de que ela é justa ou justificada, sentimento criado por um poder regulatório, pois a comoção sempre é transmitida de outro lugar, predispondo a percepção do mundo de determinada maneira, acolhendo certas dimensões e resistindo a outras. Daí afirma que a diferenciação da resposta afetiva e valoração moral são os enquadramentos que fazem com que certas vidas sejam consideradas dignas de proteção e outras não, pois "não são completamente vidas". 
médica, por total ignorância e despreparo, não conseguiu se comunicar com a mulher, a segunda criança acabou vindo a óbito. ${ }^{13}$

A barreira física encerra, contudo, apenas uma das formas de violência contra a gestante com deficiência. Mesmo quando portadoras apenas de deficiência física, com preservação de sua plena autonomia e capacidade civil, constata-se que, na realidade da vida, sua vontade é reiteradamente desconsiderada, como se constata a partir dos relatos feitos por Joyce, portadora de deficiência visual que, ao dar entrada em maternidade em Guaxupé, Minas Gerais, em 2007, recebeu a notícia de que havia mecônio no líquido amniótico, sem que fosse feito qualquer exame adicional ou the informassem de qualquer outra coisa que indicasse eventual gravidade da situação. Joyce solicitou, então, que ligassem sua médica, mas não foi atendida. A equipe decidiu realizar uma cesárea, e não admitiu a entrada de acompanhante ao centro cirúrgico. Depois de duas tentativas frustradas de anestesiá-la, optou-se por prosseguir a cirurgia "a sangue frio". "O anestesista puxava meu cabelo para eu não desmaiar de dor", relatou Joyce (LAZZAREI, 2015, s.p.).

Cuidando-se de pessoa com deficiência intelectual, a situação se mostra ainda mais dramática: se o regime codificado a considerava, a priori, incapaz, desprovida de autonomia inclusive para a prática de atos existenciais, autorreferentes, se sua vontade era irrelevante para o Direito, como exigir o respeito aos seus desejos pelos médicos? Em um sistema abstrato de incapacidade, afigurava-se, como se apontou, impossível a dissociação da capacidade para a prática de atos patrimoniais daquela necessária para atos existenciais.

Com efeito, ainda que a gestante com deficiência mental ostentasse funcionalidade suficiente para a compreensão das consequências de determinada escolha acerca de sua gestação, se ela fosse incapaz, o sistema codificado ignorava sua vontade, recusando à titular do direito existencial qualquer parcela de autonomia e capacidade para exercê-lo, o que acabava por Ihe negar a própria qualidade de pessoa humana, a conduzir a sua objetificação. E a consequência mais perversa desse processo é a naturalização da prática de atos violentos e cruéis contra a gestante com deficiência, pois, se lhe é recusada a qualidade de pessoa humana, não há dignidade a ser tutelada, admitindo-se que Ihe seja direcionada toda sorte de violência.

No Brasil, o exemplo mais emblemático e chocante desse fenômeno de reificação da pessoa com deficiência a partir da própria negação da titularidade de direitos inerentes à pessoa humana se passou no Hospital Colônia de Barbacena, fundado em 12 de outubro de 1903. O Hospital Colônia de Barbacena se tornou conhecido pelo público na década de 1980, em razão do tratamento desumano que oferecia aos pacientes, aos quais eram negados os mais básicos direitos inerentes à pessoa. O psiquiatra italiano Franco Basaglia, pioneiro na luta antimanicomial na Itália, esteve no Brasil e conheceu o hospital em 1979. Na ocasião, em uma coletiva de imprensa, desabafou: "Estive hoje num campo de concentração nazista. Em lugar nenhum do mundo, presenciei uma tragédia como essa" (CASTELO BRANCO, 2015, s.p.).

Os pacientes chegavam ao local em grandes vagões de carga, conhecidos como "trem do doido". Estima-se que, pelo menos, 60 mil pessoas tenham morrido no Hospital Colônia de Barbacena de frio, de fome, de doenças e de eletrochoques. Diante da degradante condição de asilamento, a fim de proteger suas gestações, as mulheres besuntavam suas barrigas de fezes para não serem tocadas pelos funcionários; quando conseguiam levar a gravidez a termo, após o parto, retiravam-lhes à força os bebês, que eram adotados, no mais das vezes, de forma irregular. Não havia sequer salas de partos. As parturientes tinham seus filhos nas enfermarias gerais (DUARTE, 2009, p. 188).

A superação de referido processo de negação da autonomia da gestante com deficiência e, consequentemente, da violência obstétrica a que está sujeita com maior intensidade, passa, evidentemente, pela mudança de concepção acerca da própria deficiência, como se passa a examinar.

13 O episódio é narrado na Carta Capital sob o título "Precisamos falar sobre violência contra mulheres com deficiência" (PRATES, 2016, s.p.). 


\section{O modelo social da deficiência e o regime da incapacidade estabelecido pelo Estatuto da Pessoa com Deficiência: a caminho da garantia de acesso ao parto humanizado}

O Estatuto da Pessoa com Deficiência superou algumas críticas ao regime codificado das incapacidades, estabelecendo regramento diverso para a capacidade das pessoas com deficiência no que tange, sobretudo, e ao que interessa a esta análise, à prática de atos existenciais, e mitigou, em parte, a abstrativização do regime. Ao propósito, importa sublinhar que a adoção de um novo modelo da deficiência contribuiu decisivamente para referidas mudanças.

A Classificação Internacional de Funcionalidade, Incapacidade e Saúde - CIF, divulgada pela Organização Mundial da Saúde em 2001, passou a conjugar, ao modelo médico de deficiência, o modelo social, que mormente considera a questão da deficiência um problema criado pela sociedade, e cujo principal desafio é a integração plena do indivíduo na sociedade. Sob tal perspectiva, a incapacidade não é um atributo inerente ao indivíduo, mas "um conjunto complexo de condições, muitas das quais criadas pelo ambiente social”. Com efeito, a solução do problema requer uma ação social consistente na realização das "modificações ambientais necessárias para a participação plena das pessoas com incapacidades em todas as áreas da vida social". Cuida-se, portanto, a incapacidade de uma questão política? (OMS, 2004, p. 22).

A integração do modelo médico e do modelo social inaugura a abordagem biopsicossocial da deficiência, que oferece compreensão das diferentes perspectivas de saúde: biológica, individual e social. Nesse contexto, a incapacidade é, necessariamente, "resultado tanto da limitação das funções e estruturas do corpo quanto da influência de fatores sociais e ambientais sobre essa limitação" (IBGE, 2012, p. 71). De acordo com a Classificação Internacional de Funcionalidade, Incapacidade e Saúde, deficiências "são problemas nas funções ou na estrutura do corpo, tais como um desvio importante ou uma perda" (OMS, 2004, p. 14), que nem sempre, contudo, importam em limitação da capacidade ou da funcionalidade. ${ }^{14}$

Referido modelo foi adotado expressamente pela Convenção da ONU sobre os Direitos da Pessoa com Deficiência, aprovada pelo Decreto Legislativo n. 186, em 9 de julho de 2008, passando a integrar o ordenamento jurídico brasileiro com status de emenda constitucional. Ainda no preâmbulo da Convenção, reconhece-se que a deficiência, um conceito em evolução, "resulta da interação entre pessoas com deficiência e as barreiras devidas às atitudes e ao ambiente que impedem a plena e efetiva participação dessas pessoas na sociedade em igualdade de oportunidades com as demais pessoas" (Convenção sobre os Direitos das Pessoas com Deficiência, 2011, p. 22). A propósito, afirma Mary Keys (2017, p. 265): "previous reliance solely on a narrower medical approach is no longer considered appropriate, and instead a social and human rights approach focused on removing barriers to participation is essential to the achievement of equality".

O Estatuto da Pessoa com Deficiência ${ }^{15}$ contemplou o mesmo modelo, já em seu art. $2^{\circ}$, de acordo com o qual "considera-se pessoa com deficiência aquela que tem impedimento de longo prazo de natureza física, mental, intelectual ou sensorial, o qual, em interação com uma ou mais barreiras, pode obstruir sua participação plena e efetiva na sociedade em igualdade de condições com as demais pessoas". Nos termos do $\S 1^{\circ}$ :

a avaliação da deficiência, quando necessária, será biopsicossocial, realizada por equipe multiprofissional e interdisciplinar e considerará: I - os impedimentos nas funções e nas estruturas do corpo; II - os fatores socioambientais, psicológicos e pessoais; III - a limitação no desempenho de atividades; e IV - a restrição de participação.

Essa nova perspectiva da deficiência permitiu a reformulação do regime brasileiro das incapacidades da pessoa com deficiência. De acordo com o EPD, "a pessoa com deficiência tem assegurado o direito ao

14 A CIF entende capacidade como a "aptidão de um indivíduo para executar uma tarefa ou uma acção devido a uma ou mais deficiências" e funcionalidade como "uma interação ou relação complexa entre a condição de saúde e os fatores contextuais (i.e. fatores ambientais e pessoais)" (OMS, 2004, p. 20)

15 No Brasil, o Estatuto veio tutelar aproximadamente 45,5 milhões de pessoas que, de acordo com o Censo Demográfico de 2010 , declararam ter pelo menos uma das deficiências investigadas, o que corresponde a 23,9\% da população brasileira. No que tange a cada uma das deficiências analisadas, 18,8\% das pessoas declararam ter deficiência visual; 5,1\%, auditiva; 7,0\%, motora; e 1,4\%, mental ou intelectual (IBGE, 2012, p. 73). 
exercício de sua capacidade legal em igualdade de condições com as demais pessoas" (art. 84). Afirmase, ainda, que

\begin{abstract}
a deficiência não afeta a plena capacidade civil da pessoa, inclusive para: I - casar-se e constituir união estável; II - exercer direitos sexuais e reprodutivos; III - exercer o direito de decidir sobre o número de filhos e de ter acesso a informações adequadas sobre reprodução e planejamento familiar; IV conservar sua fertilidade, sendo vedada a esterilização compulsória; $V$ - exercer o direito à família e à convivência familiar e comunitária; e VI - exercer o direito à guarda, à tutela, à curatela e à adoção, como adotante ou adotando, em igualdade de oportunidades com as demais pessoas (art. $\left.6^{\circ}\right)$.
\end{abstract}

Diante dessa nova normativa, constata-se que a regra passou a ser a capacidade e a autonomia da pessoa com deficiência. Sendo assim, resta evidente que qualquer decisão médica acerca da mulher com deficiência deve ser a ela submetida, inclusive todas aquelas que, de qualquer forma, digam respeito a sua autonomia reprodutiva e ao seu planejamento familiar. Significa, em definitivo, que a escolha entre parto normal ou cesárea, a opção por certo método contraceptivo ou ligadura de trompas, a decisão acerca de episiotomia e tricotomia, dentre diversas outras, deve ser feita, sempre que ela ostente funcionalidade suficiente para entender as consequências de tais decisões, pela mulher, que deverá ser informada acerca de todos os procedimentos, suas vantagens e desvantagens, bem como os riscos envolvidos. A informação, evidentemente, deve ser prestada de forma acessível, em linguagem clara e compatível com a possibilidade de compreensão da gestante com deficiência, devendo o médico se valer, sempre que necessário, de equipe multidisciplinar, a fim de garantir a mais perfeita apreensão da informação.

Tais decisões, de regra, sequer podem ser submetidas ao curador. De acordo com o EPD, a curatela é excepcional, constituindo "medida protetiva extraordinária e proporcional às necessidades e às circunstâncias de cada caso, e durará o menor tempo possível”, nos termos do art. 84 , caput, $\S \S 1^{\circ}$ e $3^{\circ}$. Ademais, de acordo com o art. 85 , caput e $\S 1^{\circ}$, "a curatela afetará tão somente os atos relacionados aos direitos de natureza patrimonial e negocial" e não alcançará "o direito ao próprio corpo, à sexualidade, ao matrimônio, à privacidade, à educação, à saúde, ao trabalho e ao voto".

Pela dicção dos dispositivos mencionados, a princípio, a restrição da capacidade de fato das pessoas com deficiência apenas se afigura possível para a prática de atos e negócios jurídicos relativos a situações jurídicas patrimoniais. Em relação ao exercício de direitos existenciais, o EPD impede a restrição da capacidade civil (art. $6^{\circ}$ ), além de excluir expressamente do alcance da curatela alguns direitos existenciais, dentre os quais aqueles relativos à sexualidade e ao próprio corpo (art. $85, \S 1^{\circ}$ ).

No entanto, não se pode ignorar que, em casos extremos, considerando-se a vulnerabilidade exacerbada da pessoa com deficiência, tendo em vista o grave comprometimento de sua funcionalidade, esta não terá condições de se manifestar até mesmo sobre questões existenciais, autorreferentes, que apenas a ela digam respeito. Nesses casos, a fim de melhor apoiá-la, não se vislumbra outra solução senão a intervenção protetiva do curador, que deve buscar a manifestação presumida da pessoa pautando-se em seu histórico biográfico, não procedendo puramente a uma substituição da vontade (BARBOZA; ALMEIDA, 2016, $p$. 265; MENEZES, 2016, p. 532).

A solução se justifica. Embora o Direito ostente importante papel transformador da sociedade (PERLINGIERI, 2002, p. 2-3), há de se reconhecer que há limites para essa transformação. $O$ fato de o EPD determinar que as pessoas com deficiência gozam de plena capacidade para a prática de certos atos existenciais não as fará capazes, de fato, de exercê-los por si só. A depender do grau da deficiência, do comprometimento da sua funcionalidade, do ponto de vista prático, a pessoa não conseguirá exercer tais atos autonomamente, e o Direito precisará intervir a fim de assegurar seu adequado apoio e proteção.

Destarte, a Convenção preconiza o atendimento às preferências da pessoa com deficiência psíquica ou intelectual e observa suas potencialidades para exercício de autodeterminação. Contudo, há casos extremos que exigem uma leitura excepcional, tais como o quadro concernente à pessoa com deficiência que não possui meios para exteriorizar a sua vontade, a presença de fatores a indicar forte intensificação de sua vulnerabilidade, ou ainda um contexto de outras violências e abusos.

Com efeito, em casos excepcionais, há de se admitir a flexibilização do $\S 1^{\circ}$ do art. 85 - que proíbe a curatela para os direitos nele referidos -, e do art. $6^{\circ}$ - que proíbe a restrição da capacidade civil para o 
exercício dos direitos que elenca -, para admitir que, em situação específica e pontual, para a prática de certo ato existencial, o curador submeta a questão ao juiz, que decidirá se a pessoa com deficiência pode ou não o praticar. Se, no caso concreto, a partir de análise biopsicossocial por equipe multidisciplinar, o juiz concluir que a mitigação da capacidade civil da pessoa com deficiência é o único instrumento adequado para a concretização do princípio constitucional da promoção da proteção dos direitos humanos da pessoa com deficiência e do respeito à dignidade que the é inerente, poderá afastar a regra do EPD, autorizando o curador a manifestar de acordo com a "vontade e as preferências da pessoa", vale dizer, de acordo com sua história biográfica.

Seja como for, a regra passou a ser, repita-se à exaustão, a plena capacidade da pessoa com deficiência para a prática dos atos civis e, ainda que haja alguma limitação de sua capacidade, isto não afetará o exercício de alguns direitos existenciais. Inauguram-se, assim, dois regimes jurídicos diferentes: um para o exercício de direitos patrimoniais e outro para o exercício de direitos existenciais. Trata-se de mudança fundamental voltada a garantir à considerável parcela da população brasileira a necessária autonomia para o controle sobre suas próprias decisões existenciais, interrompendo perverso ciclo de desempoderamento das pessoas com deficiência.

Essa nova perspectiva se afigura particularmente relevante para as gestantes com deficiência, já que Ihes reconhece não apenas a autonomia para decidir, sempre que ostentem a necessária funcionalidade, sobre todas as questões relativas à reprodução e ao planejamento familiar, como o direito de que todo o atendimento médico lhes seja oferecido da forma mais acessível possível, com a remoção de todas as barreiras físicas e informacionais ao pleno exercício dessa autonomia. Nessa esteira, não apenas os equipamentos médicos devem ser adequados e adaptados às gestantes com qualquer tipo de deficiência, como os médicos e enfermeiros devem ser especialmente qualificados, de modo a serem capazes, por exemplo, de se comunicar em Libras, a fim de evitar a tragédia relatada páginas acima.

Há de se assegurar, ademais, o direito às gestantes com deficiência de fazer uso do plano de parto, instrumento elaborado durante o pré-natal e que estabelece os procedimentos aos quais a gestante aceita se submeter e aqueles aos quais ela não aceita. Cuidando-se de gestante com deficiência psíquica, o plano de parto, enquanto negócio jurídico unilateral existencial, será válido se ela apresentar funcionalidades suficientes para entender as consequências de suas escolhas e mediante sua exclusiva manifestação de vontade.

Desse modo, almeja-se aliar a proteção da pessoa com deficiência à emancipação e à liberdade substantiva em atuação prospectiva do Direito, a qual, de acordo com Luiz Edson Fachin (2015, p. 86), "é a atuação hermenêutica da reconstrução permanente, correta e adequada, dos significados que se aplicam aos significantes que integram a teoria e a prática do Direito Civil".

O reconhecimento, no caso concreto, de que a gestante com deficiência ostenta a funcionalidade necessária ao exercício de sua autonomia no que tange às decisões relativas à gestação afasta, consequentemente, qualquer possibilidade de o curador se imiscuir nessas questões, inclusive no plano de parto. Se o médico optar por ignorar a vontade e os desejos da gestante - corporificados ou não no plano de parto -, e seguir a eventual orientação do curador - que, repita-se, não tem, em princípio, poderes para atuar nessa seara, salvo situação excepcional já aventada -, poderá ser responsabilizado solidariamente com o curador por violência obstétrica.

Sempre relevante recordar que, apesar de serem direitos fundamentais, de aplicabilidade imediata por controle de convencionalidade, somente meia década após a internalização da Convenção ao direito brasileiro, com status material e formal de Emenda à Constituição, ${ }^{16}$ é que houve a promulgação da Lei

\footnotetext{
16 A assinatura do tratado se deu em 30/03/2007 e sua ratificação ocorreu em 2008 pelo Congresso Nacional seguindo-se o procedimento previsto no art. $5^{\circ}, \S 3^{\circ}$ da Constituição Federal. Não se olvida do tema do "controle de Convencionalidade" das normas internas do direito brasileiro, a respeito do qual Flávia Piovesan (2012, p. 91) destaca que a proteção dos direitos humanos (human rights approach) constitui o ápice do sistema internacional e que o "controle de convencionalidade" é importante instrumento para a concretização de medidas protetivas aos direitos humanos constantes de tratados internacionais.
} 
Brasileira de Inclusão, ou Estatuto da Pessoa com Deficiência - Lei n. 13.146/2015 - na tentativa de adequar a legislação interna ao paradigma da Convenção e dar efetividade aos direitos por ela enunciados.

Daí a denúncia das dificuldades de garantia de direitos positivados em tratado internacional visando à proteção de um grupo vulnerável e os obstáculos formais e materiais colocados à frente das efetivas práticas de direitos humanos. Nessa toada, Joaquín Herrera Flores defende que os direitos humanos devem ser vistos como processos institucionais e sociais que possibilitem a abertura e consolidação de espaços de luta pela dignidade humana, reconhecendo e respeitando a pluralidade e a diversidade como marcos de uma concepção material e concreta de dignidade. $O$ autor destaca a necessidade de reafirmação desses direitos no dia a dia e por diversos agentes: "as normas jurídicas poderão cumprir uma função mais em concordância com o "que ocorre em nossas realidades" se as colocarmos em funcionamento - a partir de cima, mas sobretudo a partir de baixo -, assumindo desde o princípio uma perspectiva contextual e crítica, quer dizer, emancipadora (FLORES, 2009, p. 18).

Nada impede, evidentemente, que a própria gestante com deficiência opte pela tomada de decisão apoiada (art. 1.783-A, CC), que não repercute na sua capacidade civil, e encerra instrumento "voltado a auxiliar a pessoa que se sente fragilizada no exercício de sua autonomia", mas que reúne "condições de, por si, realizar suas escolhas e celebrar quaisquer negócios jurídicos sem a necessidade de assistência ou representação" (MENEZES, 2016, p. 42-44). Assim, o instrumento da Tomada de Decisão Apoiada poderia ser utilizado para ampliar a autodeterminação da pessoa com deficiência capaz e que demanda algum tipo de apoio para compreender o contexto de uma situação que exige sua escolha. Discute-se na doutrina nacional acerca dos objetivos da Tomada de Decisão Apoiada. Dentre esses debates, encontra-se aquele sobre sua (im)prescindibilidade para a realização exclusivamente de atos patrimoniais e a discussão sobre se a referência a "atos civis" também abarcaria as relações existências, como aqueles relativos aos direitos reprodutivos.

Contudo, como alerta David Sanchez Rubio (2014, p. 43), não basta a positivação de um direito ou um reconhecimento judicial, pois as normas jurídicas e o fenômeno jurídico se encontram em contínuo processo de significação e ressignificação, o que torna as lutas incessantes em busca do reconhecimento e efetivação dos direitos humanos, por isso almeja-se que a Tomada de Decisão Apoiada se torne realmente uma prática emancipadora para a realidade brasileira atual.

Não é despiciendo ressaltar que, em qualquer situação, por mais severa que seja a deficiência -ainda que, em hipótese excepcionalíssima, a gestante não tenha condições de exprimir sua vontade --, pelo simples (e inafastável) fato de ser sujeito de direito, dotada de inerente dignidade humana, ela sempre terá o direito fundamental ao parto humanizado. Embora o termo seja polissêmico, as propostas de humanização do parto, de uma forma geral,

\footnotetext{
[...] têm o mérito de criar novas possibilidades de imaginação e de exercício de direitos, de viver a maternidade, a sexualidade, a paternidade, a vida corporal. Enfim, de reinvenção do parto como experiência humana, onde antes só havia a escolha precária entre a cesárea como parto ideal e a vitimização do parto violento (DINIZ, 2005, p. 635).
}

E esse é um direito de todas as mulheres, independentemente de sua condição física, psíquica, social ou racial.

\section{Conclusão}

O núcleo central da temática deste trabalho é tutelar a autodeterminação dos direitos sexuais e reprodutivos, inclusive do "plano de parto", para todas as mulheres numa concepção humanizada, o que exige especificidades para as pessoas com deficiência física, psíquica ou intelectual, bem como a desvinculação de um enfoque substitutivo da vontade, sem descurar da proteção de seus interesses.

Não raro, contudo, constata-se que os saberes médico-científicos dos profissionais da saúde se sobrepõem e tolhem as liberdades individuais das gestantes e conduzem à nefasta prática de violência 
obstétrica, que abarca ofensas aos direitos sexuais e reprodutivos, assim como à liberdade e autonomia da mulher, numa evidente violação de direitos humanos fundamentais. Se a prática da violência obstétrica já é gravosa em si própria, maior ainda é a ofensa quando intentada contra pessoas em situações de hipervulnerabilidade, como o são as pessoas com deficiência, que sempre estiveram estigmatizadas e desprovidas de autonomia diante do modelo médico de deficiência, contemplado na codificação civil de 1916 e de 2002.

A internalização da Convenção de Nova lorque sobre os Direitos das Pessoas com Deficiência e, posteriormente, em 2015, a edição do Estatuto da Pessoa com Deficiência, alteraram substancialmente o tratamento jurídico dado às pessoas com deficiência.

Primeiramente, concebe-se a deficiência a partir de um complexo de condições biopsicossociais, considerando-se fatores sociais e ambientais exteriores, mas também aspectos individuais. Posteriormente, vislumbra-se novo regime jurídico conferido às incapacidades tidas como excepcionais, quando se delimitam atos patrimoniais e existenciais, sendo que a pessoa com deficiência passa a ser, como regra e a priori, absolutamente capaz para o exercício de sua autodeterminação, especialmente no que diz respeito aos atos de natureza personalíssima.

Essa nova perspectiva se afigura, portanto, como importante mecanismo que respeita e tutela a autonomia da gestante para decidir sobre as questões relativas ao planejamento familiar, à gestação, ao parto (possibilitando-Ihe decidir, no "plano de parto" ou por meio da tomada de decisão apoiada, sobre os procedimentos a que aceita ou não se submeter) e ao próprio corpo, no exercício de seus direitos e liberdades existenciais de maneira humanizada. Para tanto, devem-se reduzir as barreiras (físicas, comunicacionais, de conhecimento etc.) que afastam o exercício de sua autodeterminação e o poder de decisão da pessoa com deficiência sobre questões relativas à sua personalidade, conjugando-se a proteção formal e a material da dignidade da gestante com deficiência.

Conquistas e retrocessos constituem a dinâmica dialética de movimentos e práticas de reconhecimento e afirmação de direitos humanos e fundamentais de grupos vulneráveis. As pessoas com deficiência passam pelo mesmo dificultoso trilhar. Urge, na contemporaneidade, reflexões a fim de expandir a compreensão dos nortes traçados pela Convenção, sob pena de a autonomia persistir restrita e condicionada a padrões culturais que inferiorizam, daí a necessidade do juízo crítico e emancipatório em prol da efetiva autodeterminação.

\section{Referências}

BARBOZA, Heloisa Helena. Vulnerabilidade e cuidado: aspectos jurídicos. In: PEREIRA, Tânia da Silva; OLIVEIRA, Guilherme de (coord.). Cuidado e vulnerabilidade. São Paulo: Atlas, 2009. p. 106-118.

BARBOZA, Heloisa Helena. O princípio do melhor interesse do idoso. In: PEREIRA, Tânia da Silva; OLIVEIRA, Guilherme de (coord.). O cuidado como valor jurídico. Rio de Janeiro: Forense, 2008. p. 57-72.

BARBOZA, Heloisa Helena; ALMEIDA JÚNIOR, Vitor. A capacidade à luz do Estatuto da Pessoa com Deficiência. In: MENEZES, Joyceane Bezerra de (org.). Direito das pessoas com deficiência psíquica e intelectual nas relações privadas: Convenção sobre os direitos das pessoas com deficiência e Lei Brasileira de Inclusão. Rio de Janeiro: Processo, 2016. p. 249-274.

BRASIL. Lei n. 11.108, de 7 de abril de 2005. Altera a Lei n=8.080, de 19 de setembro de 1990, para garantir às parturientes o direito à presença de acompanhante durante o trabalho de parto, parto e pósparto imediato, no âmbito do Sistema Único de Saúde - SUS. Disponível em: http://www.planalto.gov.br/ ccivil_03/_Ato2004-2006/2005/Lei/L11108.htm. Acesso em: 8 dez. 2018.

BRASIL. Lei n. 10.406, de 10 de janeiro de 2002. Institui o Código Civil. Disponível em: http://www. planalto.gov.br/ccivil_03/LEIS/2002/L10406.htm. Acesso em: 8 dez. 2018.

BRASIL. Convenção sobre os Direitos das Pessoas com Deficiência. Protocolo Facultativo à Convenção sobre os Direitos das Pessoas com Deficiência: decreto legislativo n 186, de 09 de 
julho de 2008; decreto $n^{\circ} 6.949$, de 25 de agosto de 2009. 4. ed. rev. e atual. Brasília: Secretaria de Direitos Humanos, Secretaria Nacional de Promoção dos Direitos da Pessoa com Deficiência, 2011. Disponível em: http://www.pessoacomdeficiencia.gov.br/app/sites/default/files/publicacoes/ convencaopessoascomdeficiencia.pdf. Acesso em: 8 dez. 2018.

BUTLER, Judith. Quadros de guerra: quando a vida é passível de luto? Rio de Janeiro: Civilização Brasileira, 2015.

CASTELO BRANCO, Thayara. O Holocausto manicomial: trechos da história do maior hospício do Brasil! Justificando, São Paulo, 03 maio 2015. Disponível em: http://justificando.cartacapital.com. br/2015/03/05/o-holocausto-manicomial-trechos-da-historia-do-maior-hospicio-do-brasil/. Acesso em: 28 fev. 2018.

COSTA, Mariana V. de M.; LUNA, Maria J. de M. A violência obstétrica e a dominação masculina de Bourdieu. In: SEMINÁRIO INTERNACIONAL DE DIREITOS HUMANOS DA UFPB, IX. João Pessoa, 2016. Anais [...]. João Pessoa: Universidade Federal da Paraíba, 2016. Disponível em: http:www.ufpb. br/evento/lti/ocs/index.php/ixsidh/paper/view/4245/159. Acesso em: 6 set. 2018.

DIAS, João Álvaro. Procriação assistida e responsabilidade médica. Coimbra: Coimbra Editora, 1996.

DINIZ, Carmen Simone Grilo. Humanização da assistência ao parto no Brasil: os muitos sentidos de um movimento. Ciência e Saúde Coletiva, Rio de Janeiro, v. 10, n. 3, p. 627-637, jul./set. 2005.

DINIZ, Carmen Simone Grilo; NIY, Denise Yoshie; ANDREZZO, Halana Faria de Aguiar; CARVALHO, Priscila Cavalcanti Albuquerque; SALGADO, Heloisa de Oliveira. A vagina-escola: seminário interdisciplinar sobre violência contra a mulher no ensino das profissões de saúde. Interface Comunicação, Saúde, Educação, Botucatu, v. 20, n. 56, p. 253-259, jan.-mar. 2016.

DUARTE, Maristela Nascimento. De “Ares e Luzes" a "Inferno Humano”. Concepções e práticas psiquiátricas no Hospital Colônia de Barbacena: 1946-1979. Estudo de caso. 2009. Tese (Doutorado em História) - Instituto de Ciências Humanas e Filosofia, Universidade Federal Fluminense, Niterói, 2009. Disponível em: http://www.historia.uff.br/stricto/td/1100.pdf. Acesso em: 4 set. 2018.

FACHIN, Luiz Edson. Direito civil: sentidos, transformações e fim. Rio de Janeiro: Renovar, 2015.

FLORES, Joaquín Herrera. A (re)invenção dos direitos humanos. Tradução de Jefferson Aparecido Dias, Carlos Roberto Diogo Garcia e Antônio Henrique Graciano Suxberger. Florianópolis: Fundação Boiteux, 2009.

FOUCAULT, Michel. Vigiar e punir. Petrópolis: Vozes, 1997.

FUNDAÇÃO PERSEU ABRAMO. Mulheres brasileiras e gênero nos espaços público e privado. Brasil, São Paulo, 2010. Disponível em: https://apublica.org/wpcontent/uploads/2013/03/www.fpa_.org_. br_sites_default_files_pesquisaintegra.pdf. Acesso em: 5 set. 2018.

HENCl, Goer. Cruelty in maternity wards: fifty years later. The Journal of Perinatal Education, [S.I.], v. 19, n. 3, p. 33-42. 2010. Disponível em: https://www.ncbi.nlm.nih.gov/pmc/articles/PMC2920649/?tool=p mcentrez\&report=abstract\#bib24. Acesso em: 5 set. 2018.

HUGO, Victor. O Corcunda de Notre Dame. Tradução de Jorge Bastos. Rio de Janeiro: Zahar, 2013. Disponível em: https://sanderlei.com.br/PDF/Victor-Hugo/Victor-Hugo-O-Corcunda-de-Notre-Dame.pdf, p. 180. Acesso em: 11 set. 2018.

INSTITUTO BRASILEIRO DE GEOGRAFIA E ESTATÍSTICA - IBGE. Censo demográfico de 2010. Brasil, 2012. Disponível em: https://biblioteca.ibge.gov.br/visualizacao/periodicos/94/cd_2010_religiao_ deficiencia.pdf. Acesso em: 8 dez. 2018.

KEYS, Mary. Article 12 [Equal Recognition Before the Law]. In: DELLA FINA, Valentina; CERA, Rachele; PALMISANO, Giuseppe. The United Nations Convention on the Rights of Persons with Disabilities: a commentary. Switzerland: Springer International Publishing, 2017. p. 89-106.

KONDER, Carlos Nelson. Vulnerabilidade patrimonial e vulnerabilidade existencial: por um sistema diferenciador. Revista de Direito do Consumidor, São Paulo, v. 99, p. 101-123, maio-jun. 2015. 
Disponível em: http://konder.adv.br/wp-content/uploads/2018/01/Carlos-Nelson-Konder-Vulnerabilidadepatrimonial-e-vulnerabilidade-existencial-In-Revista-de-Direito-do-Consumidor.pdf. Acesso em: 11 set. 2018.

LAZZERI, Thais. Vítimas da violência obstétrica: o lado invisível do parto. Época, São Paulo, 04 ago. 2015. Disponível em: https://epoca.globo.com/vida/noticia/2015/08/vitimas-da-violencia-obstetrica-o-ladoinvisivel-do-parto.html. Acesso em: 3 set. 2018.

MENEZES, Joyceane Bezerra de. O direito protetivo após a Convenção sobre os direitos da pessoa com deficiência, o novo CPC e o Estatuto da Pessoa com Deficiência. In: MENEZES, Joyceane Bezerra de (org.). Direito das pessoas com deficiência psíquica e intelectual nas relações privadas:

Convenção sobre os direitos das pessoas com deficiência e Lei Brasileira de Inclusão. Rio de Janeiro: Processo, 2016. p. 509-544.

MENEZES, Joyceane Bezerra de. Tomada de decisão apoiada: instrumento de apoio ao exercício da capacidade civil da pessoa com deficiência instituído pela Lei Brasileira de Inclusão (Lei n. 13.146/2015). Revista Brasileira de Direito Civil - RBDCivil, Rio de Janeiro, v. 9, p. 31-57, jul./set. 2016. Disponível em: https://rbdcivil.ibdcivil.org.br/rbdc/article/view/53/47. Acesso em: 9 set. 2018.

ORGANIZAÇÃO MUNDIAL DA SAÚDE - OMS. Classificação internacional de funcionalidade, incapacidade e saúde. Lisboa, 2004. Disponível em: http://www.inr.pt/uploads/docs/cif/CIF_port_\%20 2004.pdf. Acesso em: 3 set. 2018.

ORGANIZAÇÃO MUNDIAL DA SAÚDE - OMS. Prevenção e eliminação de abusos, desrespeito e maus-tratos durante o parto em instituições de saúde. Suíça, 2014. Disponível em: http://apps. who. int/iris/bitstream/handle/10665/134588/WHO_RHR_14.23_por.pdf;jsessionid=C49D2B650CF14F6CBFB7 5244721125D6?sequence=3. Acesso em: 3 set. 2018.

PERLINGIERI, Pietro. Perfis do direito civil: introdução ao direito civil constitucional. Tradução de Maria Cristina De Cicco. Rio de Janeiro: Renovar, 1999.

PERLINGIERI, Pietro. Perfis do direito civil: introdução ao direito civil constitucional. Tradução de Maria Cristina De Cicco. 3. ed. Rio de Janeiro: Renovar, 2002.

PIOVESAN, Flávia. Direitos humanos e diálogo entre jurisdições. Revista Brasileira de Direito Constitucional - RBDC, São Paulo, n. 19, p. 67-93, jan./jun. 2012.

PRATES, Deborah. Precisamos falar sobre violência contra mulheres com deficiência. Carta Capital, São Paulo, 21 nov. 2016. Disponível em: http://justificando.cartacapital.com.br/2016/11/21/precisamosfalar-sobre-violencia-contra-mulheres-com-deficiencia/. Acesso em: 3 set. 2018.

RUBIO, David Sanchez. Encantos e desencantos dos direitos humanos: de emancipações, libertações e dominações. Porto Alegre: Livraria do Advogado, 2014.

SÃO PAULO. Defensoria Pública do Estado de São Paulo - DPGE-SP. A violência obstétrica existe. São Paulo, 2013. Disponível em: https://www.defensoria.sp.def.br/dpesp/repositorio/41/violencia\%20 obstetrica.pdf. Acesso em: 5 set. 2018.

WHO. Individualized, supportive care key to positive childbirth experience, says WHO. Switzerland, 2018. Disponível em: http://www.who.int/mediacentre/news/releases/2018/positive-childbirth-experience/ en/. Acesso em: 14 maio 2018.

WOLFART, Graziela. A retomada do protagonismo feminino no parto. Revista do Instituto Humanitas Unisinos, São Leopoldo, n. 396, p. 11-14, 2 jul. 2012.

Recebido em: $14 / 12 / 2018$

Aprovado em: 15/02/2019 